\title{
Study of the relationship between the size of the minimum wage with the achieved socio- economic indicators
}

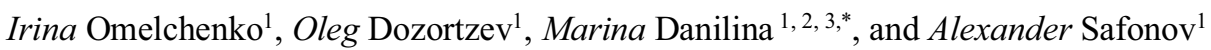 \\ ${ }^{1}$ Research Institute VNII of Labour, Ministry of Labour of Russia, Russia \\ ${ }^{2}$ Finance University under the Government of the Russian Federation, Russia \\ ${ }^{3}$ Russian Economic University, Russia
}

\begin{abstract}
The authors of this article focused on another aspect of poverty and carried out regression analysis of the data influencing the formation of the minimum wage in the labour market in the constituent entities of the Russian Federation. The authors determined the fact of leveling the importance of the federal minimum wage as a tool to influence the level of economic development of regions and reduce poverty. Also, the performed regression analysis revealed a statistically significant effect of poverty and unemployment rates on the decline in real wages in the constituent entity of the Russian Federation. Thus, the analysis showed that the main factors influencing the establishment of the minimum wage in the region are the median wages, the gross regional product of the subject and the subsistence minimum of the TN. Fixed capital investments do not directly affect the level of minimum wages.
\end{abstract}

\section{Introduction}

In the contemporary world poverty deals with many questions, which are in focus of many researchers. Are there ways for the poor to improve their lives, and what is preventing them from being able to do these things? [1] How can the chronically poor escape poverty? Chronic poverty is a varied and complex phenomenon, but at its root is powerlessness. Poor people expend enormous energy in trying to escape poverty, but with few assets, little education, and chronic ill health, their struggle is often unsuccessful. [2] Why has eradiating poverty not been a more urgent global issue? [3] How serious threat do disasters and climate change pose to our prospects of eliminating extreme poverty in the next two decades? [4].

The authors of this article focused on another aspect of poverty and carried out regression analysis of the data influencing the formation of the minimum wage in the labour market in the constituent entities of the Russian Federation:

- the level of the subsistence minimum of the able-bodied population;

- population size;

- investments in fixed assets per capita;

\footnotetext{
* Corresponding author: marinadanilina@yandex.ru
} 
- the level of employment in the informal sector;

- unemployment rate;

- the level of nominal accrued wages;

- median wages;

- subsidies for equalizing budgetary provision per capita;

- gross regional product;

- the level of poverty.

The details of these research are presented below.

\section{Materials and methods}

Based on the content analysis, it was found that the legislation limits the level of minimum wages in the regions of the Russian Federation - the minimum wage cannot be lower than the federal minimum wage, which leads the regions to the need to set the minimum wage at the minimum wage even in cases where it is economically unjustified, which further increases " monetary overhang "in the region, increasing the degree of stratification of society into citizens included in the contour of redistribution of state subsidies for interbudgetary equalization (mainly in state-owned enterprises of the budget sector) and citizens not included in these contours (mainly in the extra-budgetary sector), and forming citizens have a dependent mood.

This leads to the erosion of the low-skilled labor market in the constituent entity of the Russian Federation due to the fact that it becomes unjustifiably expensive. At the same time, a highly qualified workforce is forced to receive wages at the level of low-skilled, which reduces the incentives for participants in labor relations to invest in human capital. The result of this process is the lack of growth in labor productivity in the region.

The result of this financial impact is the crowding out of private investment by state subsidies and a recession in the real sector of the region's economy. The formation of a wide public sector in the constituent entities of the Russian Federation, with a significant amount of subsidies for ensuring intergovernmental equalization, leads to widespread hidden unemployment and relative poverty.

It is possible to reduce the severity of these problems by reducing the "monetary overhang" and restoring market pricing for labor in the constituent entities of the Russian Federation. Note also that the densely populated region plays a positive role in this case. More populated regions have a more developed labor market, which reduces the unemployment rate (correlation coefficient - minus 0.34 ) and the poverty level (correlation coefficient - minus 0.39 ).

On the other hand, in more densely populated regions, it is possible to attract a larger amount of labor, which is insignificantly related to a decrease in the volume of investments in fixed assets (the correlation coefficient is minus 0.14 ). The dense population of the subject removes restrictions on the development of the region's economy due to the potential depth of the labor market.

All of the above arguments state the fact of leveling the importance of the federal minimum wage as a tool to influence the level of economic development of regions and reduce poverty.

Also, the performed regression analysis revealed a statistically significant effect of poverty and unemployment rates on the decline in real wages in the constituent entity of the Russian Federation.

Thus, the analysis showed that the main factors influencing the establishment of the minimum wage in the region are the median wages, the gross regional product of the subject and the subsistence minimum of the TN. Fixed capital investments do not directly affect the level of minimum wages (Table 1). 
Table 1. Correlations between the main studied indicators.

\begin{tabular}{|l|l|l|l|l|}
\hline & $\begin{array}{c}\text { Fixed capital investment } \\
\text { per capita }\end{array}$ & GRP per capita & PM TN & \multicolumn{1}{|c|}{$\begin{array}{c}\text { Minimum } \\
\text { wage }\end{array}$} \\
\hline $\begin{array}{l}\text { Fixed capital } \\
\text { investment per } \\
\text { capita }\end{array}$ & 1 & & & \\
\hline GRP per capita & 0,9899588 & 1 & & \\
\hline PM TN & 0,638713309 & 0,7067103 & 1 & \\
\hline Minimum wage & 0,621916235 & 0,672966 & 0,7782896 & 1 \\
\hline
\end{tabular}

The above factors are interrelated, but this is taken into account and the analysis is adjusted to avoid the influence of factors on each other.

Nevertheless, the indirect impact of investments in fixed assets on the minimum wage exists through the launch of economic growth processes that lead to an increase in the GRP of the subject. The growth of the GRP leads to an increase in the income of the population, which raises the median wages. The adaptation of market prices to the new economic situation leads to their growth. Because of this, the regional PM of the TN rises, and after it the minimum wage is pulled up.

The historically formed features of the economic development of the constituent entities of the Russian Federation lead to the fact that the productivity of jobs created in the course of economic growth does not affect the level of minimum wages.

Territorial and economic differentiation of the constituent entities of the Russian Federation leads to the need to redistribute funds between them. The redistribution of funds is mainly due to subsidies to the regions to equalize budgetary provision.

Subsidizing the regions has two important consequences: first, there is an increase in the subsistence minimum of the $\mathrm{TN}$ and the minimum wage by financing them to the level of the federal minimum wage; secondly, there is a substitution of private investments by state ones due to economically unjustified high labour prices.

This causes a crisis in the labor market, due to the rise in the cost of labor, which is becoming especially noticeable in the real sector of the economy, where the cost of lowskilled labor is approaching the price of highly skilled labor. The result is an increase in the cost of products and services, which leads to non-competitiveness and stagnation of the regional economy. When an attempt is made to increase subsidies to maintain the rate of economic growth, the "subsidy spiral" is unfolding.

At the same time, a "monetary overhang" is formed in the regions from subsidized money, unsecured by an equal volume of goods and services, which accelerates the rate of inflation and impedes economic development.

At the same time, in the constituent entities of the Russian Federation, where the market-based level of the minimum wage is equal to or higher than the minimum wage, its establishment at the federal level does not make economic sense.

The analysis of the largest and smallest PMs of TN in the RF shows the following. So, in the Chukotka Autonomous Okrug, PM TN in the IV quarter of 2019 is 22365 rubles, which is significantly higher than the established federal minimum wage. A citizen who receives a salary in the amount of the minimum wage for his labor activity will not be able to live on the wages received. And the value of the PM in the Voronezh region is 8894 rubles. Accordingly, low-skilled labor, paid in the amount of the minimum wage, becomes unjustifiably expensive, approaching in price to more highly skilled labor. 


\section{Results}

The analysis showed the presence of strong statistical relationships between a number of indicators used. The median wages are highly correlated with the level of investment in fixed assets (the correlation coefficient is 0.71 ). The level of GRP per capita has an almost linear relationship with the level of investment in fixed assets (the correlation coefficient is 0.98). At the same time, investments in fixed assets do not have a direct impact on the unemployment rate (the correlation coefficient is minus 0.08 ) and the decrease in the region's subsidies (the correlation coefficient is minus 0.14). Nevertheless, an increase in the level of investment in fixed assets has a positive effect on solving the problem of poverty (the correlation coefficient is minus 0.26 ).

The level of investment in fixed assets is not associated with the creation of highly productive jobs or their growth (correlation coefficients: -0.04 and -0.05 , respectively). On the other hand, the number of already created high-performance jobs and their growth have a strong statistical relationship (the correlation coefficient is 0.98 ). This indicates that the creation of such jobs occurs only in certain constituent entities of the Russian Federation, where a pool of highly productive jobs has already been created. This situation is probably due to the creation in a number of regions of innovation clusters that are not related to the regional economy, which is still dominated by jobs with low labour productivity.

It was also revealed that investments have a high level of impact on wages and GRP of a constituent entity of the Russian Federation, forming its economic base. The development of the economic base of the region contributes to an increase in its competitiveness and the formation of a local labor market, which makes it possible to reduce poverty and, to a greater extent, indirectly, the amount of federal subsidies that the region needs. It follows that the level of economic development of the region has a significant impact on the size of wages.

Note that an increase in poverty leads to the need to increase subsidies (correlation coefficient - 0.51), the number of people employed in the informal sector (correlation coefficient - 0.21) and a decrease in investment in fixed assets (correlation coefficient minus 0.14). An increase in the level of subsidies leads to the emergence of a "subsidy spiral", since a high level of subsidies further reduces the competitiveness of the region, which requires an increase in the volume of subsidies.

A significant level of poverty, causing the need for subsidizing the region, is caused by the need to pay low-skilled labor at a level not lower than the federal minimum wage. Even in cases where the actual price of labor is below the minimum wage, the employer is forced to pay it by virtue of the law. This results in higher labor costs and lowers the producer's profit that can be invested in production. In turn, this slows down economic growth.

These interrelationships show that the inflow of federal money into the economy of the constituent entity of the Russian Federation makes the recipient subject dependent on federal funding, with the development of which it becomes economically expedient for the region to maintain its lagging position in order to obtain guaranteed federal funds, rather than develop the regional economy.

In addition, the inflow of subsidized money into the regional economy contributes to an increase in wages in the private sector, as it provides a higher level of payment in the public sector compared to the market-justified level, thereby creating a "money overhang" in the economy of the subject. All this, in the end, contributes to an increase in market prices and an increase in unemployment (the correlation coefficient is 0.31 ), as well as the number of poor citizens who remain outside the contours of the redistribution of cash flows from subsidies. 
All of the above arguments state the fact of leveling the importance of the federal minimum wage as a tool to influence the level of economic development of regions and reduce poverty.

Also, the performed regression analysis revealed a statistically significant effect of poverty and unemployment rates on the decline in real wages in the constituent entity of the Russian Federation.

Thus, the analysis showed that the main factors influencing the establishment of the minimum wage in the region are the median wages, the gross regional product of the subject and the subsistence minimum of the TN. Fixed capital investments do not directly affect the level of minimum wages.

\section{References}

1. Banerjee, A. V., \& Duflo, E. Poor economics: A radical rethinking of the way to fight global poverty. New York: Public Affairs. (2011).

2. Chronic Poverty Research Centre. The chronic poverty report 2008-09: Escaping poverty traps. Manchester: Chronic Poverty Research Centre. (2009).

3. Hulme, D. Global Poverty: How global governance is failing the poor. Abingdon, UK: Routledge. (2010).

4. Shepherd, A., Mitchell, T., Lewis, K., Lenhardt, A., Jones, L., Scott, L., \& Muir-Wood, R. The geography of poverty, disasters and climate extremes in 2030. London: ODI. (2013). 